\title{
CRYSTALLINE CHROMIUM DOPED ALUMINUM OXIDE (RUBY) USE AS A LUMINESCENT SCREEN FOR PROTON BEAMS*
}

\author{
K. A. Brown, D. M. Gassner" \\ Brookhaven National Laboratory, Upton, NY 11973, USA
}

\begin{abstract}
In our search for a better luminescent screen material, we tested pieces of mono-crystalline chromium doped aluminum oxide (more commonly known as a ruby) using a $24 \mathrm{GeV}$ proton beam. Due to the large variations in beam intensity and species which are run at the Alternating Gradient Synchrotron (AGS), we hope to find a material which can sufficiently luminesce, is compatible in vacuum, and maintain its performance level over extended use. Results from frame grabbed video camera images using a variety of neutral density filters are presented.
\end{abstract}

\section{INTRODUCTION}

A study of luminescent properties of four test materials mounted on a variable position plunged actuator was conducted. The flag materials were installed at a $45^{\circ}$ angle to the beam. The light emitted from the flag leaves the vacuum enclosure through a transparent quartz port, then reflected $90^{\circ}$ by a mirror to the video camera which was mounted parallel to the beam path.

\section{HARDWARE}

\subsection{Flag materials}

Two of the materials tested were poly-crystalline aluminum oxide pieces, one doped with $\mathrm{Cr}_{2} \mathrm{O}_{3}$, the other undoped. These were supplied by Morgan Matrox Inc. commercially called Chromox $\left(\mathrm{Al}_{2} \mathrm{O}_{3} 99.4 \%, \mathrm{Cr}_{2} \mathrm{O}_{3} 0.5 \%\right)$, average grain size $10-50 \mathrm{um}$. Chromox and radlin (zinc cadmium sulfide, $40 \%$ cadmium by weight, by $\mathrm{MCI}$ Optonix, commercial name Optex PFG) are the present flag materials used for diagnostics in the slow extracted beam lines, and the upstream portion of the fast extracted beam line.

The other two pieces were mono-crystalline aluminum oxide (ruby) doped with different amounts of $\mathrm{Cr}_{2} \mathrm{O}_{3}$. Union Carbide Corporation Crystal Products provided the $0.22 \%$ doped piece (1.5 mm thick), and Crystal Optics Research, Inc. supplied the $0.05 \%$ piece (1 mm thick).

\footnotetext{
* Work performed under auspices of the U. S. Department of Energy.

"Email: gassner@bnl.gov
}

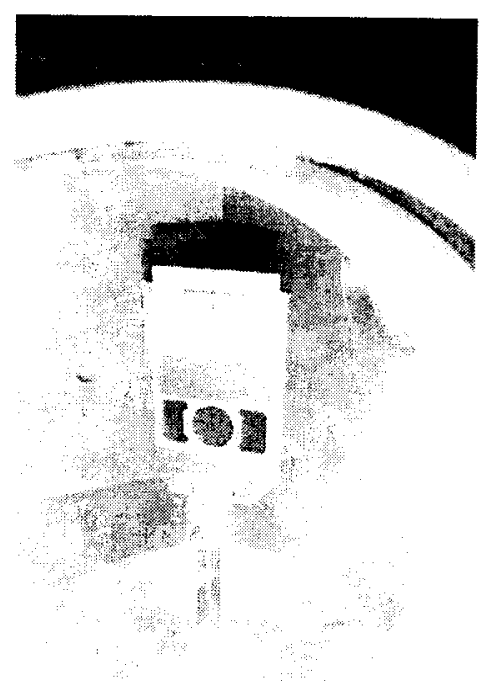

Figure 1: The picture above is the view looking into the vacuum chamber (typical transport vacuum is 10 microns or $10^{-2}$ torr) at the four test materials. From top to bottom: doped aluminum oxide, undoped aluminum oxide, ruby $0.22 \%$ doped, and a round ruby $0.05 \%$ doped. The location of the test assembly is 157 feet from the AGS ring. The beam travels left to right.

These commercially available laser grade rubies were manufactured using the Czochralski production technique. The ruby price and availability is attractive due the popular use of ruby lasers in industry. In fact, the majority of the cost is for cutting and polishing of the surfaces.

\subsection{Video camera}

We used the Dage-MTI Inc. 70R video camera. The camera head (with 1" vidicon tube) is separate from the camera control unit, it is specifically designed for use in high radiation environments. For linearity purposes the automatic gain control was disabled, and the auto black compensation had a negligible effect due to the presence of a reference near absolute black in the image.

A remote control neutral density filter assembly is mounted between the camera lens and vidicon tube. It has four filters $(0.5,1,1.5,2)$ which can supply attenuation variations up to 100,000 . 


\subsection{Framegrabber}

The VME based framegrabber is the Modular Vision Computer (MVC) by Imaging Technology Inc. which operates at $40 \mathrm{MHz}$ with a pipeline processing configuration.

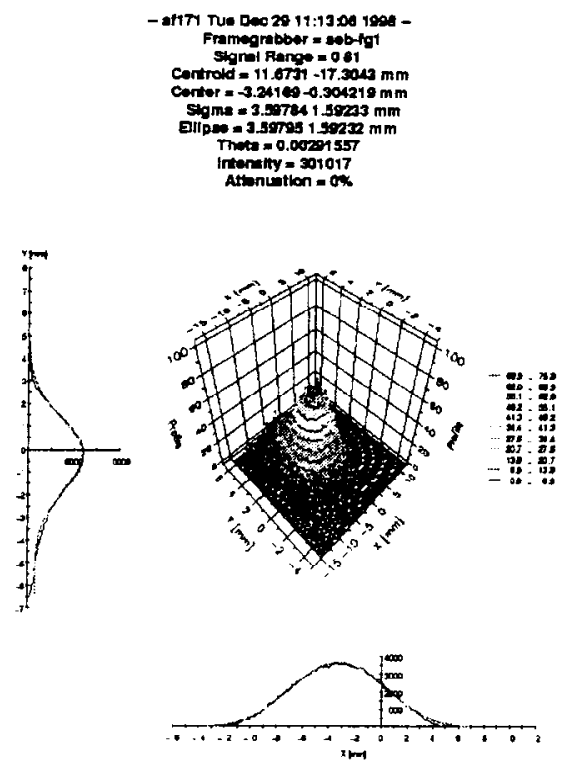

Figure 2: Sample data from framegrabber application.

An onboard modular histogram processor produces the horizontal and vertical projections. The image was displayed via an application written for our Sun Solaris controls system. The digitised image $(512 \times 480)$ pixel values can range from $0-255$ ( 8 bits).

\section{TEST TECHNIQUE}

The flag materials were individually positioned into the path of the $24 \mathrm{GeV}$ slow extracted proton beam from the AGS. The beam was spilled out at rate of 14 teraprotons $/ \mathrm{sec}$. (for $2.5 \mathrm{sec}$.) or average current 2.2 microamps. One set of data was acquired at $0.2 \mathrm{pa}$, which was our typical intensity during a polarized proton run.

Data from the framegrabber was analysed by determining the value of the peak pixels in the center of the beam spot. Neutral density filters were remotely inserted until the peak pixel values were in the lower half of the full response range. This was done to avoid saturation and stay in the linear response of the system.

\section{RESULTS}

The data in table 1 shows the peak pixel values for the camera's response to the chosen combinations of test materials and neutral density filters.

Table 1: Data from flag material study.

\begin{tabular}{|l|l|l|l|l|l|}
\hline $\begin{array}{l}\mathrm{ND} \\
\text { Filter } \\
\text { Atten. }\end{array}$ & $\begin{array}{l}\text { Beam } \\
\text { Current }\end{array}$ & $\begin{array}{l}\text { Ruby } \\
.05 \%\end{array}$ & $\begin{array}{l}\text { Ruby } \\
.22 \%\end{array}$ & $\begin{array}{l}\mathrm{Al}_{2} \mathrm{O}_{3} \\
\text { Undoped }\end{array}$ & $\begin{array}{l}\mathrm{Al}_{2} \mathrm{O}_{3} \\
\text { Doped }\end{array}$ \\
\hline $1 / 3160$ & 2.2 ua & 32 & 30 & 0 & 18 \\
\hline $1 / 1000$ & 2.2 ua & 96 & 85 & 0 & 51 \\
\hline $1 / 31.6$ & 2.2 ua & sat. & sat. & 55 & sat. \\
\hline None & $0.2 p a$ & 20 & 17 & 0 & $<5$ \\
\hline
\end{tabular}

The undoped poly-crystalline aluminum oxide produced about 30 times less light than the doped version. The emitted light from the polished ruby was less dispersed than the other materials.

The mono-crystalline material produced roughly twice more light than the poly-crystalline.

\section{SUMMARY}

A factor of two more light is emitted from monocrystalline rubies verses the poly-crystalline material. Slightly higher peak levels from the polished ruby due to less scattering of the emitted light.

We intend to use the mono-crystalline ruby (which is more compatible in a vacuum environment) as an alternative to radlin which will out gas under vacuum.

\section{ACKNOWLEDGMENTS}

We acknowledge the contributions of the AGS Beam Components \& Instrumentation Group, Jon Hock, Larry Hoff, Steve Tepikian, James C. Smith (Crystal Optics Research, Inc.), and Colin Johnson (CERN). 